\title{
Enhancing Children's Event Recall after Long Delays
}

\author{
DAVID LA ROOY ${ }^{1 *}$, MARGARET-ELLEN PIPE $^{1}$ and \\ JANICE E. MURRAY ${ }^{2}$ \\ ${ }^{1}$ Section on Social and Emotional Development, National Institute of Child Health and Human \\ Development, USA \\ ${ }^{2}$ Department of Psychology, University of Otago, Dunedin, New Zealand
}

\begin{abstract}
SUMMARY
The effects of context reinstatement as means of enhancing 5- and 6-year-old children's event memory in repeated interviews after a 6-month delay were examined. Children were interviewed immediately after the event (baseline interview) and twice at a 6-month delay, with 24 hours between interviews. The first 6-month interview was conducted in a perfect-context reinstatement $(n=15)$, imperfect-context reinstatement $(n=16)$, or no-context reinstatement $(n=15)$ condition. The second 6-month interview was conducted 24 hours later with no-context reinstatement for all children. Context reinstatement attenuated the effects of delay on recall. The accuracy of the details reported was greater in the perfect-context compared to the imperfect-context and no-context conditions. Details repeated between the immediate-baseline interview and in the first 6-month interview were more accurate than details repeated between the first and second 6-month interview. There was no increase in recall (hypermnesia) across the first and second 6-month interviews in any condition. Practical implications of these findings are discussed. Copyright (C) 2006 John Wiley \& Sons, Ltd.
\end{abstract}

When children are witnesses to or victims of a crime, in all probability they will be interviewed about the experience on multiple occasions. For example, a decade ago Ceci and Bruck (1993) estimated that children were questioned an average of 11 times during an investigation of suspected abuse. The frequency of repeated interviews may be declining; more recently, the Scottish Executive Central Research Unit (Plotnikoff \& Woolfson, 2001) and a study of Los Angeles County dependency court cases (Malloy, Lyon, \& Quas, 2005 ) both found that children had been interviewed four times on average, with the actual number of interviews ranging from a single interview to twenty eight. Nonetheless, repeated interviews are clearly the norm. Given that this is the case, what effects do repeated interviews have on children's testimony, either positive (increasing the amount of information reported and/or its accuracy) or negative (in particular, decreasing accuracy)? The research reported here was motivated by this question and builds on an emerging line of research that has important theoretical as well as practical implications (e.g. La Rooy, Pipe, \& Murray, 2005). In the current study we examined the effects of repeatedly interviewing children about an event following short and long delays between interviews

*Correspondence to: Dr D. La Rooy, Faculty of Arts \& Social Sciences, Kingston University, Penrhyn Road, Kingston upon Thames, KT1 2EE, UK. E-mail: david@larooy.net 
and asked, specifically, (i) whether the accuracy of new information reported in successive interviews depended on the delay between interviews as has been suggested previously (La Rooy et al., 2005) and (ii) whether reinstatement of the event context would enhance the amount and the accuracy of recall in repeated interviews after a long delay.

\section{REPEATED INTERVIEWING}

The advantages of repeated recall attempts in memory tasks are well documented in laboratory studies with adults. Repeated testing of to-be-remembered items typically leads to recall of previously unrecalled details across tests, a phenomenon referred to as reminiscence, and sometimes also to an increase in the number of details recalled across tests, referred to as hypermnesia (e.g. Erdelyi \& Becker, 1974; Payne, 1986; Roediger \& Payne, 1982; for reviews, see Erdelyi, 1996; Payne, 1987). For hypermnesia to occur, successive recall tests must contain new information, that is, there must be reminiscence. However, since previously recalled information may be omitted across recall tests (trial-totrial forgetting), for hypermnesia to occur the amount of new information must exceed the amount that is forgotten across trials. Thus, reminiscence is a necessary but not sufficient condition for hypermnesia. Further, because some information may be forgotten across tests, hypermnesia is not necessarily an accurate reflection of the magnitude of the reminiscence effect. The two phenomena need to be examined separately to understand how recall changes as a function of repeated attempts and time.

Applied studies have shown that these phenomena, reminiscence and hypermnesia, may also occur when adults recall events they have witnessed (Bluck, Levine, \& Laulhere, 1999; Bornstien, Liebel, \& Scarberry, 1998; Dunning \& Stern, 1992; Scrivner $\&$ Safer, 1988). Indeed, the convergence of results from applied and laboratory studies with adults is compelling given the variety of to-be-remembered stimuli (e.g. a televised event, video clips, lists of words and pictures), the recall context (e.g. interviews and written responses) and delay to testing ranging from a few minutes to several months (e.g. Bluck et al., 1999; Bornstien et al., 1998; Dunning \& Stern, 1992; Erdelyi \& Becker, 1974; Payne, 1986; Roediger \& Payne, 1982; Scrivner \& Safer, 1988). These studies have generally used free recall to elicit event details, rather than questions or probes that tap recognition memory. Given that information obtained in free recall is typically more accurate than that elicited by more specific questions, it is perhaps not surprising that the general finding has been increased recall of correct information with only relatively minor increases in errors.

Comparatively few studies have examined reminiscence and hypermnesia in children's recall either in laboratory or applied settings. The earliest research on the phenomena was conducted by Ballard (1913) who observed that 12-year-old children's memory for lines of poetry increased between a test immediately after the poem was initially memorized and a test conducted 2 days later, and this finding was later replicated by Ammons and Irion (1954). More recent research testing children's memory has shown effects of reminiscence when pictures or words are used as the to-be-remembered information (Howe, Kelland, Bryant-Brown, \& Clark, 1992; Paris, 1978). These two studies were inconsistent with respect to age effects, with Paris (1978) reporting hypermnesia for 11-year-old, but not 8year-old children, and Howe et al. (1992) finding hypermnesia for similar (71/2- and 10year-old) age groups. 
Hypermnesia has also been observed with even younger children when recalling personally experienced events. La Rooy et al. (2005) examined 5- and 6-year-old children's verbal recall across repeated interviews about an event in which they had participated. When children were interviewed using free recall and open-ended cues, immediately after the event and again 24 hours later, both reminiscence and hypermnesia occurred. Further, the new details reported in the repeated interview were highly accurate (92\%, Experiment 1).

When the repeated interviews both occurred after a 6-month delay (Experiment 3), less new information was reported in the second interview, and accuracy also declined (72\%). However, the accuracy of the new information is relatively high compared to several previous studies finding that new information across repeated interviews is likely to be highly inaccurate (e.g. Peterson, Moores, \& White, 2001; Pipe, Gee, Wilson, \& Egerton, 1999; Salmon \& Pipe, 1997, 2000; Steward et al., 1996). Typically, in these studies only $50 \%$ or less of the additional items of information recalled were accurate.

Thus, both positive (increases in amount of information recalled) and negative effects (decreases in accuracy of new information recalled) have been observed in children's event memory. In all of these studies reporting high error rates in previously unreported information, however, the repeated interviews were separated by delays of months and years, rather than 24 hours as in La Rooy et al. (2005), suggesting that it is the delay between repeated interviews, rather than the delay since the event that determines the accuracy of the additional information gained by repeated interviewing. One objective of the current study was to examine this possibility directly, by comparing the amount and accuracy of new information reported across a long (6-month) delay between interviews, and a short (24-hour) delay between interviews conducted 6 months after the event. The practical significance of this comparison is straightforward; recommendations regarding the likely reliability of previously unreported information may depend on the delay between the interviews.

\section{CONTEXT REINSTATEMENT}

It is also important, from a practical perspective, to find ways of enhancing recall, in terms of both the amount and the accuracy of the information reported, when interviews are, of necessity, delayed. One potential means of enhancing recall is through the reinstatement of the context in which an event occurred at the time of the memory test (Godden \& Baddeley, 1980). Context reinstatement effects are predicted by the principle of encoding specificity (Tulving \& Thomson, 1973), according to which the greater the congruence between the contexts of encoding and recall, the greater the amount of information accurately recalled. The principle of encoding specificity explains how information could be intact in memory, but at the same time not be reported in an interview; in some situations the retrieval cue(s) needed to recover a memory are not present. Moreover, specific retrieval cues may be particularly important following very long delays, particularly for the recall of specific details or accessing verbatim memory (Brainerd, Reyna, Howe, \& Kingma, 1990).

Consistent with the original experimental studies of context reinstatement (e.g. Godden \& Baddeley, 1980), reinstating the actual physical context of an event at the time of interview has been shown to be beneficial as a means of facilitating children's event recall (e.g. Hershkowitz et al., 1998; Orbach, Hershkowitz, Lamb, Sternberg, \& Horowitz, 2000; Pipe \& Wilson, 1994; Priestley, Roberts, \& Pipe, 1999; Wilkinson, 1988; Wilson \& Pipe, 
1989). Physical context reinstatement has been effective in enhancing the recall of both younger (3- and 4-year-old) children (Wilkinson, 1988) as well as older (5- to 6-year-old and 9- to 10-year-old) children (Pipe \& Wilson, 1994). Increases in the amount recalled have also been found when participants mentally reinstate the event context as in the cognitive interview (McCauley \& Fisher, 1995; Memon, Wark, Bull, \& Koehnken, 1997; Saywitz, Geiselman, \& Bornstein, 1992).

Interestingly, studies with non-human animals and young infants have demonstrated that context reinstatement can have delayed effects. Indeed, some of the most powerful demonstrations of the effects of physical context reinstatement came from studies in which exposure to the event (or learning) context occurred prior to the memory test, in the reminder paradigm (e.g. Hayne \& Rovee-Collier, 1995; Rovee-Collier, 1995, RoveeCollier, Hayne, \& Colombo, 2000; Spear, 1973). Similar effects have also been found with very young children (Sheffield \& Hudson, 1994) as well as with older children (Priestley et al., 1999). Priestley et al. (1999), for example, interviewed 5- to 7-year-old children 6 months after they had taken part in an event, a pirate visit, in one of three conditions; with reinstatement of context items at the time of interview, exposure to the same items 24 hours prior to the interview (the reminder condition), or no-context reinstatement. Context reinstatement, whether at the time of interview or as a reminder 24 hours prior to it, was effective in increasing the amount of correct information compared to no context reinstatement.

Such studies suggest that the mechanism of context reinstatement is reactivation of the memory representation, making it more available for recall. In repeated interviews, context reinstatement might not only enhance recall at the time, but also lead to the recall of additional new information in a subsequent memory interview. Alternatively, context reinstatement might be effective because it attenuates forgetting, that is, minimizes omissions of previously recalled information in subsequent tests. In the present study, therefore, we examined whether context reinstatement would enhance recall at the 6-month delay and whether the effects were because of recall of new information (i.e. reminiscence) or a decrease in forgetting. It is also possible, of course, that context reinstatement may both facilitate reminiscence and reduce forgetting, conditions that would maximize the opportunity to obtain hypermnesia.

From a practical perspective it is important to examine the extent to which reinstatement of the context needs to be perfect to have beneficial effects; specifically we examined whether the substitution of context items with items that were not part of the original event both reduces the effectiveness of context reinstatement, a possibility raised by Orbach et al. (2000), and leads to errors. Over time in the real world the physical context in which an event has occurred may change, with some items being removed and others being added, and these changes may constitute a possible source of errors reducing the effectiveness of the context reinstatement (Orbach et al., 2000). We know from previous research on suggestibility that when children's attention is specifically drawn to misleading items, props, or dolls, they have a tendency to incorporate incorrect details into their accounts (e.g. Gee \& Pipe, 1995; Leichtman \& Ceci, 1995). However, we do not know how perfect the context reinstatement needs to be in order for it to remain an effective memory cue, or, conversely, the extent to which 'scene-contaminating' items become incorporated into children's accounts in openended interviews when there has been no deliberate attempt to mislead children. The question we address, therefore, is whether imperfect-context reinstatement alone (i.e. without misleading questioning and/or direction) is sufficient to decrease accuracy thereby mitigating the potential benefits of context reinstatement in real-world settings. 


\section{OVERVIEW}

We examined, first, the effects on 5- to 6-year-old children's event recall across repeated interviews separated by either 6 months or 24 hours and second, the effects of reinstating the event context at a long delay. Children in this age range are of particular interest from an applied perspective because although they have sufficient verbal skills to be witnesses and on occasion to give testimony, their open-ended accounts are likely to be less complete than those of older children. A 6-month delay was chosen based on previous research with the event used in the present study. We wanted to test whether recall could be enhanced once some forgetting had occurred and Jones and Pipe (2002) had shown that statistically significant forgetting of this event was evident by 6 months although not earlier. We expected that context reinstatement at the time of the interview would enhance recall (both amount and accuracy) compared with no-context reinstatement, based on physical context serving as a retrieval cue enabling access to information that would otherwise go unreported.

Five- and six-year-old children took part in an event (visiting the pirate) and were interviewed immediately (baseline) in a nearby classroom, and again 6 months later. At the 6-month delay, the children took part in two interviews, separated by 24 hours. The interview format for the baseline interview and the two 6-month interviews was the same for all children and consisted of an open invitation for the children to recall all that they could, after which four open-ended cues were provided. The first 6-month interviews took place in one of three context conditions. Children in the 'perfect-context' reinstatement condition were interviewed in the room in which they had experienced the original event with all of the event items in place. Children in the 'imperfect-context' reinstatement condition were interviewed in the room in which they experienced the event with half of the event items in place and half of the original items replaced by new items. Children in the no-context reinstatement condition were interviewed in a nearby classroom without context reinstatement. In the second 6-month interview all children were interviewed in the classroom without context reinstatement.

\section{METHOD}

\section{Participants}

Forty-six 5- and 6-year-old children (20 male and 26 female) participated. The average age of children in each condition was similar; they were $73(S D=7.5), 73(S D=6.5)$ and 74 $(S D=6.5)$ months old in the perfect-context, imperfect-context and no-context conditions, respectively. The children were predominantly New Zealanders of European extraction. Written permission for the children to participate was provided by their caregivers and children's assent was obtained at each session.

\section{Materials}

\section{Event items}

The 'pirate event' was based on an event similar to that described by Murachver, Pipe, Gordon, Owens, and Fivush (1996) and comprised four scenes with each, in turn, consisting of five main activities. To create a distinctive pirate context, there was a large 
wooden cutout of a boat in front of four large panels $(120 \mathrm{~cm}$ wide and $180 \mathrm{~cm} \mathrm{high})$ depicting a pirate scene. A net was thrown over the boat, gold bars and coins arranged next to it. A desk covered by a cloth was in the centre of the activity area. Twenty-eight items were used in the four scenes as follows: Scene 1 involved a hoistable sail, drum, drum sticks, waistcoat, name book, skeleton pen, and a brown box; Scene 2 involved a water jug, jar for dye, eyedropper, bowl, paint brush, map paper, and a red magic box; Scene 3 involved a pirate poem written on a scroll, toy parrot, bird cage, bird seeds, a seed scoop, telescope, and a steering wheel; and Scene 4 involved a key, treasure map, spade, barrel full of polystyrene chips, treasure chest, jewels, and a padlock.

\section{Context reinstatement items}

At the 6-month delay, children in the perfect-context condition were presented with the event items they had seen during the visit to the pirate 6 months earlier. Children in the imperfect-context condition were presented with 14 of the original 28 event items, and a set of 14 distracter items that were new. The distracter items were a green box, a puzzle, stepping-stones cut from vinyl, a silver bell, a rope, a message in a bottle, a red anchor, a big bear in a vest, a pink tea pot and cup, a weather vane, a red plastic hammer, a blue plastic saw, a mop, and a fishing rod. The substitution of items was counterbalanced across the four scenes of the event for children in the imperfect-context reinstatement condition; for half the children in this condition all of the original items in Scenes 1 and 4 were present, with the distracter items replacing items in Scenes 2 and 3. For the remaining children the original items were presented in Scenes 2 and 3, and the distracter items replaced items in Scenes 1 and 4.

\section{Procedure}

Prior to participation in the event, the children were assigned to the perfect-context, imperfect-context and no-context conditions so that the number of males and females at each school were evenly distributed across conditions. Two interviewers interviewed the same number of males and females in each condition at each school.

The children participated in the pirate event individually and the pirate (a female research assistant) was blind to the context reinstatement condition to which the children had been assigned. An assistant guided the children individually from their class, and the event began when they reached the pirate's room and the assistant asked the children to bang on the door loudly. The pirate opened the door. After an introduction, the assistant left and the child performed the event activities. In Scene 1 the activities were hoisting a sail, banging a drum with drum sticks, putting a pirate waistcoat on, shaking the pirate's hand, and writing their name in a pirate book with a skeleton pen. In Scene 2, the activities surrounded the making of 'magic paint'. Water was poured from a jug into a bowl, an eyedropper was used to add dye, the paint was mixed with the brush and then the magic treasure map was painted. The map was then placed in a magic red box to dry. In Scene 3, the children read aloud the poem on the old scroll, fed the toy parrot using the seed scoop, looked through a telescope, steered the ship and danced a jig. In Scene 4, the map in the red box was transformed (by magic) to a 'real' treasure map and was removed, the children followed the treasure map to a large pink barrel. They removed the lid from the barrel, and then dug in the barrel containing the styrofoam chips with a spade, until they discovered the treasure chest. Using the key placed nearby they opened the treasure chest to reveal items of jewellery. Throughout the event the pirate used empty language to encourage the children to perform the activities, that is, 
without specifically mentioning any item or action that would be later coded as correctly recalled information about the event. The entire event lasted no longer than 15 minutes.

Immediately following the event, children were individually interviewed about the pirate visit (baseline interview) and again, twice, 6 months later. Each interview was identical in format and began with an open invitation for the children to recall, in their own words, everything that they could remember about the event. In an effort to elicit as many details as possible during free recall the interviewer nodded appreciatively and responded to what the children said by saying 'that sounds like fun, can you tell me what else happened?' Once a child had recalled all that they could, the interviewer introduced four open-ended cues in an attempt to elicit further information. The four open-ended cues referred to the overall goal of each scene of the event. The first cue was 'I heard that the first thing you had to do was meet the pirate, I bet you have to do lots of fun things for that, tell me what they were'; second, 'It sounds like you had to do some special things to get the map ready, tell me what they are'; third, 'What about the pirate key, what sorts of things did you do with that?'; and fourth, 'I heard that the last thing you had to do was find the treasure, how did you do that?' When children could report no further details in response to a cue, the interviewer introduced the next open-ended cue. On completion of each interview, following presentation of all the cues, the interviewer gave the children a small gift such as a coloured pencil.

At the first 6-month interview, the only difference between the no-context, perfectcontext and imperfect-context interview conditions was the context in which the children were interviewed. In the no-context condition, interviews were conducted in the room in which immediate-baseline interviews had been conducted (which was different from the pirate event room). In the perfect-context condition the interview took place in the room in which children had visited the pirate, with all props and items set out as they had been at the time of the event. Before the interview began, the interviewer guided the children around the scene and told them that the pirate room was the same as when they visited the pirate, except for the interviewer's desk and chair. For children in the imperfect-context condition the instructions and procedure were the same as in the perfect context condition with the following exception; the interviewer added that he/she had tried to bring all the same things back, but that some of the things might have been mixed up and could be different. The time that children took to look around the set ranged between 60 and 100 seconds. Children were not allowed to touch any of the items and were instructed not to speak during this phase. However, 10 of the children began talking and they were interrupted by the interviewer who said 'just look now and we can talk about it all in a while'.

For all children, the second 6-month interview was conducted in the room in which the immediate-baseline interviews, and the no-context reinstatement 6-month interviews, had been conducted. At the beginning of the second 6-month interview, the interviewer said that it was important he/she find out exactly what had happened and asked the children to again try as hard as they could. The interviewer told the children that they should report anything else that they remembered as well as everything that they reported the day earlier. The same interviewers who conducted the baseline interviews also conducted the first and second 6-month interviews. However, at the 6-month delay each interviewer interviewed children they had not previously interviewed in the baseline interview. Five of the children were interviewed 2 days rather than 1 day after the first 6-month interview (two children from the perfect-context condition and three children from the imperfect-context condition) because of snowstorm. All interviews were audio- and videotaped. Written transcripts were made of all interviews and were used for coding. 


\section{Coding and inter-rater agreement}

Children in each condition (perfect, imperfect and no context) were credited with recall of correct details relating to the 28 actions and 28 objects from the pirate event. For example, a report that they had, 'hoisted the sail' was coded as a correct mention of the action 'hoist' and a correct mention of the object 'sail'. Credit was also given for mention of actions and objects in isolation, for example, if a child said, 'I hoisted something', they received credit for the recall of 'hoist'. Repetitions of correct information within an interview did not receive further credit, whether made in response to the initial free-recall invitation, or in response to any of the four open-ended cues that followed. No credit was given for mention of actions and objects that were provided in the open-ended cues (i.e. chest, key and unlock). Errors were coded as being distracter-related (descriptions of activities involving the objects used as distracter items in the imperfect-context reinstatement condition) or non-distracter related (actions and objects that had not been part of the event and incorrect description of items from the event).

Two independent raters coded one-third of the transcripts from the immediate-baseline interview, and the first and second 6-month interviews. Inter-rater agreement was calculated as the number of coding agreements/agreements + disagreements (Tinsley \& Weiss, 2000). Equal numbers of transcripts were chosen from each condition for coding. The coders were unaware of the interview condition and gender of the children. Inter-rater agreement was $88 \%, 86 \%$ and $86 \%$ for the immediate-baseline interview, and the first and second 6-month interviews respectively. The codes from one of the raters, the first author, were used in analyses that follow.

\section{RESULTS}

Cohen's $f$ statistics were calculated to measure the size of the significant effects (Cohen, 1988); for reference, $f$ statistics of $0.10,0.25$ and 0.40 indicate small, medium and large effects respectively. We chose the same number of participants in the current experiment as was used by Priestley et al. (1999) in a similar study of context reinstatement, and performed a power analysis based on the size of the context reinstatement effect and the variance reported by Priestley et al. (1999). This analysis indicated that a minimum of 15 participants per group was required. We report all the results relating to our main predictions whether or not they are significant. Non-significant results that are not of direct interest are omitted. Preliminary analyses were conducted to examine effects of interview phase (free vs. cued recall), interviewer identity (Interviewer 1 or 2) and gender across the repeated interviews and interview contexts. There were no effects of these variables and they did not receive further consideration.

\section{Correct recall}

First, we examined whether the total number of correct details recalled changed across successive interviews, and whether any change was influenced by interview context at the 6-month delay. Because all children were interviewed in the same (no-context) condition in the immediate-baseline interview, an effect of interview context would be indicated by an interaction between interview context and interview delay. An analysis of variance (ANOVA) performed with interview context (perfect, imperfect or no context) as a 


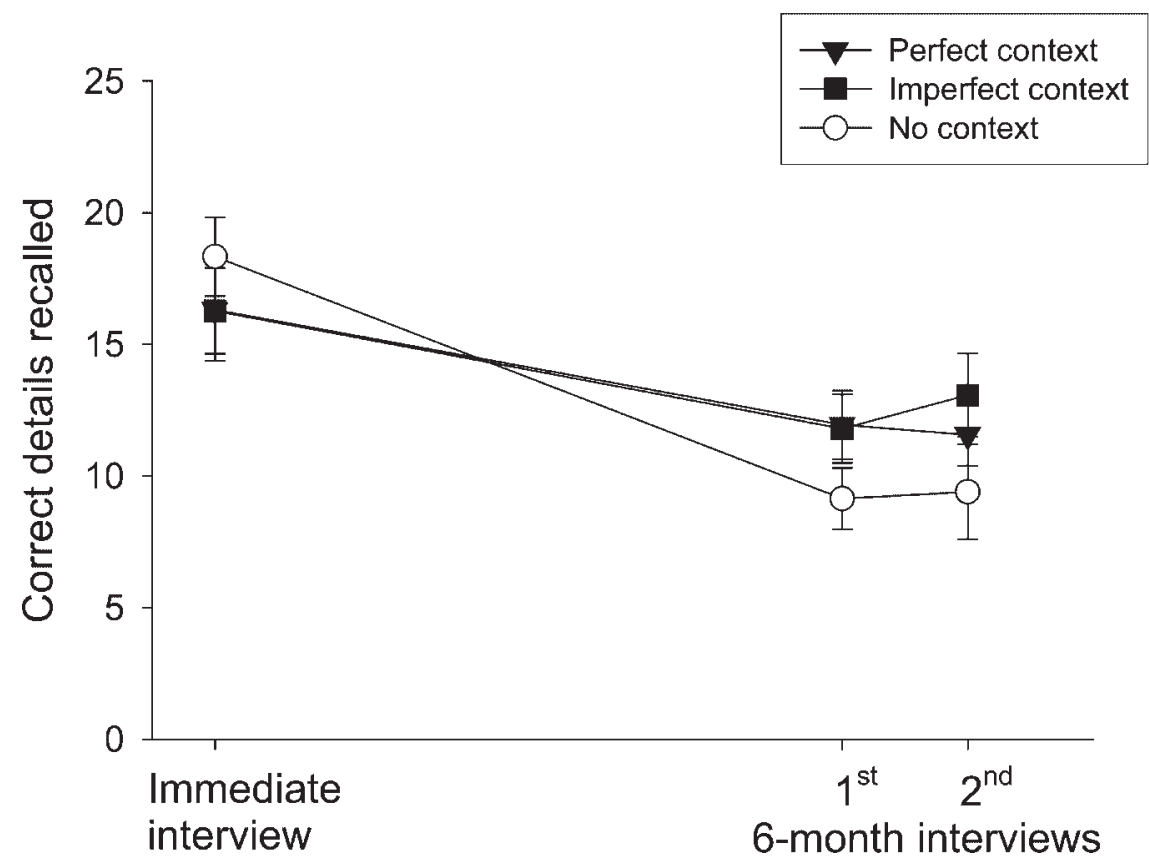

Figure 1. Total number of correct details recalled at the immediate-baseline interview and the first and second 6-month interviews

between-subjects factor and interview delay (immediate baseline, first 6 month and second 6 month) as a within-subjects factor revealed a main effect of interview delay, $F(2,86)=34.49, p<0.001, f=0.90$, and an interaction between interview delay and interview context $F(4,86)=2.85, p<0.05, f=0.36$. The main effect of interview context was not significant, $F<1, f=0.12$.

Post hoc Student-Newman Keuls (SNK) tests of the means failed to reveal differences between the interview contexts at any of the three interview delays. However, Figure 1 shows that although there was a decrease in the amount of correct information recalled from the immediate-baseline interview to the first 6-month interview for all three groups, the interaction reflects an attenuation of forgetting for children in the two context reinstatement groups, relative to the no-context reinstatement group. Analysis of difference scores, calculated by subtracting the amount recalled in the first 6-month interview from the immediate-baseline interview, showed that recall decreased by $50 \%$ for children in the no-context condition, compared to $27 \%$ for children interviewed with perfect-context reinstatement and imperfect-context reinstatement combined, $t(44)=2.41, p<0.05$.

Second, a separate analysis of the two 6-month interviews was conducted to examine whether either inter-interview delay or context reinstatement led to any differences in the recall of new and repeated information, respectively, and whether hypermnesia occurred between the first and second 6-month interviews. A mixed-model ANOVA, with the type of details reported (new or repeated) and 6-month interview ${ }^{1}$ (first or second) as withinsubjects factors, and interview context (perfect, imperfect or no context) as a betweensubjects factor showed no significant increase in the total number of correct details (new

\footnotetext{
${ }^{1}$ It was not possible to include the details recalled in the immediate-baseline interview in this analysis because they could only be categorized as new.
} 
Table 1. Correct Details (and $S D$ )

\begin{tabular}{lcccr}
\hline & $\begin{array}{c}\text { Perfect } \\
\text { context }(n=16)\end{array}$ & $\begin{array}{c}\text { Imperfect } \\
\text { context }(n=15)\end{array}$ & $\begin{array}{c}\text { No context } \\
(n=15)\end{array}$ & $\begin{array}{c}\text { Marginal } \\
\text { mean }(n=46)\end{array}$ \\
\hline Immediate-baseline interview & $16.31(7.79)$ & $16.27(6.32)$ & $18.33(5.82)$ & $16.96(6.64)$ \\
First 6-month interview & & & & \\
$\quad$ New & $4.63(2.96)$ & $4.27(3.53)$ & $2.47(1.12)$ & $3.80(2.85)$ \\
$\quad$ Repeated & $7.31(4.83)$ & $7.53(4.47)$ & $6.67(4.03)$ & $7.17(4.38)$ \\
$\quad$ Total & $11.94(5.25)$ & $11.80(5.05)$ & $9.14(4.52)$ & $10.97(5.01)$ \\
Second 6-month interview & & & & \\
$\quad$ New & $3.69(1.92)$ & $4.00(2.80)$ & $2.87(2.20)$ & $3.52(2.32)$ \\
$\quad$ Repeated & $7.87(4.83)$ & $9.07(5.16)$ & $6.53(4.24)$ & $7.83(4.76)$ \\
$\quad$ Total & $11.56(4.72)$ & $13.07(6.14)$ & $9.40(4.56)$ & $11.35(5.28)$ \\
\hline
\end{tabular}

Note: New and repeated correct details were computed relative to the preceding interview; for the first 6-month interview this was relative to the immediate-baseline interview ( 6 months between interviews); for the second 6month interview this was relative to the first 6-month interview ( 24 hours between interviews).

and repeated combined) reported across the 6-month interviews, $F<1, f=0.14$, no effect of interview context, $F(2,43)=1.77, p=0.18, f=0.29$, and no interaction between the 6month interviews and interview context, $F(2,43)=1.27, p=0.29, f=0.24$. A repeated interview at the 6-month delay did not lead to hypermnesia, independent of the context in which children were interviewed; as can be seen in Table 1, the overall marginal mean was $10.97(S D=5.01)$ in the first 6-month interview and $11.35(S D=5.28)$ in the second 6month interview. The analysis also revealed no interaction between the type of details reported (new or repeated) and the interview context, $F(2,43)=0.09, p=0.91, f=0.06$, indicating that the context reinstatement did not differentially facilitate the recall of new and repeated information, although, about twice the number of details reported in the interviews were repeated (66\%) than were new $(33 \%), F(1,43)=29.62, p<0.001, f=0.83$ (Table 1). The interaction between the 6-month interview (first or second) and the type of details reported (new or repeated) was not significant, nor was the 3-way interaction of all the factors in this analysis.

\section{Accuracy}

Accuracy was calculated as correct details reported/(correct details + errors), following Salmon and Pipe (1997, 2000), and an arcsine transformation was performed on the scores before analysis (Zar, 1996). First, we compared the accuracy of children's recall across the three interviews in an analysis with interview context (perfect, imperfect or no context) and interview delay (immediate baseline, first 6 month and second 6 month) as factors. There was a main effect of delay, $F(2,86)=28.75, p<0.001, f=0.82$, and a main effect of interview context, $F(1,43)=4.51, p<0.05, f=0.46$. Although the interaction between these factors did not reach significance, $F(4,86)=1.49, p=0.21, f=0.26$, the a priori prediction was of a difference only following the introduction of context reinstatement. $t$-tests showed that at the first 6-month interview accuracy was highest for children experiencing perfect-context reinstatement $(M=0.88, S D=0.13)$ compared with imperfect-context reinstatement $(M=0.75, S D=0.16), t(29)=2.98, p<0.001$, and that recall in these conditions did not differ compared to the no-context reinstatement condition 
Table 2. Accuracy (and $S D$ )

\begin{tabular}{lcccc}
\hline & $\begin{array}{c}\text { Perfect } \\
\text { context }(n=16)\end{array}$ & $\begin{array}{c}\text { Imperfect } \\
\text { context }(n=15)\end{array}$ & $\begin{array}{c}\text { No context } \\
(n=15)\end{array}$ & $\begin{array}{c}\text { Marginal } \\
\text { mean }(n=46)\end{array}$ \\
\hline $\begin{array}{l}\text { Immediate-baseline interview } \\
\text { First 6-month interview }\end{array}$ & $0.95(0.06)$ & $0.94(0.06)$ & $0.93(0.08)$ & $0.94(0.07)$ \\
$\quad$ New & $0.75(0.26)$ & $0.48(0.26)$ & $0.63(0.25)$ & $0.62(0.28)$ \\
$\quad$ Repeated & 1 & 1 & $0.98(0.03)$ & $0.99(0.02)$ \\
$\quad$ Total & $0.88(0.13)$ & $0.75(0.16)$ & $0.81(0.19)$ & $0.81(0.17)$ \\
Second 6-month interview & & & & \\
$\quad$ New & $0.68(0.29)$ & $0.61(0.35)$ & $0.44(0.27)$ & $0.58(0.32)$ \\
$\quad$ Repeated & $0.92(0.11)$ & $0.86(0.15)$ & $0.89(0.19)$ & $0.89(0.16)$ \\
$\quad$ Total & $0.84(0.15)$ & $0.73(0.21)$ & $0.70(0.18)$ & $0.76(0.19)$ \\
\hline
\end{tabular}

The accuracy of new and repeated details were computed relative to the preceding interview; for the first 6-month interview this was relative to the immediate-baseline interview ( 6 months between interviews); for the second 6month interview this was relative to the first 6-month interview ( 24 hours between interviews).

$(M=0.81, S D=0.19) . t$-tests of accuracy at the second 6-month interview showed that accuracy was highest for children who experienced perfect-context reinstatement $(M=0.84, S D=0.15)$ compared with the imperfect-context reinstatement $(M=0.73$, $S D=0.21), t(29)=2.06, p<.05$, and no-context reinstatement $(M=0.70, S D=0.18)$, $t(29)=2.53, p<0.01$, which did not differ (Table 2).

To examine the accuracy of new and repeated details following a long inter-interview delay (6 months) and following a short interview delay (24 hours) a mixed-model ANOVA with type of details (new or repeated) and 6-month interview ${ }^{2}$ (first or second) as withinsubjects factors, and interview context (perfect, imperfect or no context) as a betweensubjects factor. Accuracy of repeated information was significantly higher than that of new information, $F(1,41)=195.34, p<0.001, f=2.81$, and accuracy decreased between the first and second 6-month-interview, $F(1,41)=15.77, p<0.001, f=0.62$. These effects were modified by a 3-way interaction between the type of detail (new or repeated), 6-month interview (first or second) and interview context (perfect, imperfect or no context), $F(2,41)=3.37, p<0.05, f=0.41$ (Table 2 ). The remaining main effects and interactions were not significant.

To further explore the above 3-way interaction, the accuracy of new and repeated information was analysed in separate analyses, with interview context and 6-month interview as factors. For new information, the only significant effect was that of interview context, $F(2,43)=3.23, p<0.05, f=0.39$. Post hoc SNK tests confirmed that the accuracy of new information was highest in the perfect-context condition $(M=0.72, S D=0.23)$ when compared to the imperfect-context $(M=0.55, S D=0.24)$ and the no-context condition $(M=0.54, S D=0.16)$ which did not differ.

For repeated details there was a significant main effect of 6-month interview, $F(1,41)=34.24, p<0.001, f=0.91$. The accuracy of repeated details decreased from 0.99 $(S D=0.02)$ to $0.89(S D=0.16)$ between the first and second 6-month-interviews respectively. Thus, somewhat paradoxically, repeated information was more accurate with long delays between interviews (i.e. between the immediate-baseline interview and the

\footnotetext{
${ }^{2}$ It was not possible to include the accuracy of details recalled in the immediate-baseline interview in this analysis because they could only be categorized as new.
} 
first 6-month interview) than with short delays (i.e. between the first and second 6-month interviews). There were no other significant main effects or interactions in this analysis.

\section{Distracter-related errors}

Although the imperfect-context interview did not result in an overall decrease in accuracy in the 6-month interviews, the presence of the misleading items may nonetheless have had an influence on the kinds of errors children made. To examine whether this was the case, we examined distracter-related errors, that is, errors relating to the substitute items in the imperfect-context reinstatement condition. Distracter-related errors were few in number despite the distracter items themselves comprising $50 \%$ of the physical items in the imperfect-context reinstatement interview. The number of distracter-related errors was $1.60(S D=1.72)$ in the first 6-month interview and $1.33(S D=1.91)$ in the second 6-month interview. In the no-context condition, the corresponding means were $0.07(S D=0.26)$ and $0.20(S D=0.77)$ in the first and second 6-month interviews respectfully, indicating a small chance occurrence of 'distracter-related errors'. Children in the perfect-context condition made no distracter-related errors. However, although the average number of distracterrelated errors was low, from a practical perspective, the number of children referring to them is important. A Chi-square analysis, $\chi^{2}=22.55, p<0.001$, confirmed that in the first 6-month interview almost all children who made distracter-related errors were in the imperfect-context condition; distracter-related errors were made by 10 children in the imperfect-context condition $(n=15), 1$ child in the no-context condition $(n=15)$ and no children in the perfect-context condition $(n=16)$. In the second 6-month interview similar results were obtained, $\chi^{2}=13.51, p<0.01$, and seven children in the imperfect-context condition made at least one distracter-related error, whereas only one child in the nocontext condition, and none in the perfect-context condition made distracter-related errors. Therefore, despite the average number of distracter-related errors being low, over half of the children in the imperfect-context condition made specific reference to at least one distracter item. This happened when interviews occurred in the presence of distracters (in the first 6-month-interview), as well as 24 hours later when the distracters were no longer present (in the second 6-month interview).

\section{DISCUSSION}

We examined whether the amount and accuracy of information recalled across repeated interviews was influenced by the delay between interviews and the context in which the interviews were conducted. Consistent with previous studies (Pipe \& Wilson, 1994; Priestley et al., 1999; Wilkinson, 1988; Wilson \& Pipe, 1989), forgetting was attenuated by context reinstatement; the difference between the amount recalled at the immediatebaseline interviews and the first 6-month interview was the greatest for children interviewed without context reinstatement. Context reinstatement could potentially have enhanced recall by increasing the amount of reminiscence (the recall of new details) and/or reducing interview-to-interview omissions of previously recalled details (forgetting), both of which are necessary conditions for hypermnesia. Analysis of the number of correct details recalled, however, did not show effects for either new or repeated details examined separately. Thus, there was no evidence that context reinstatement specifically increased 
reminiscence or reduced interview-to-interview omissions of previously recalled details across the first and second 6-month interviews. Rather, the effect of attenuated forgetting appears to be because of the combined effects of context on reminiscence and forgetting.

The benefits of context reinstatement were also observed in the overall accuracy of the details recalled, which persisted at the 6-month interview conducted 24 hours later. Children interviewed with perfect-context reinstatement in the first 6-month interview were more accurate than children interviewed with imperfect-context reinstatement in both 6-month interviews. This suggests that the quality of context reinstatement is important for it to benefit recall; if the original context has changed or been degraded there will likely be a cost to accuracy. Note, however, that there was no difference in accuracy between children interviewed with imperfect- and no-context reinstatement at either interview; that is, the detrimental effect on accuracy of the 'contaminated' context did not result in overall more errors than the more usual 'out of context' interview condition. This is consistent with Pipe and Wilson (1994) who also found that imperfect-context reinstatement did not increase errors rates over and above those obtained with no-context reinstatement. Prior studies also suggest, however, that imperfect-context reinstatement causes decreases in accuracy when children are asked directly about the distracter items (Gee \& Pipe, 1995) or interact with them (Salmon, Bidrose, \& Pipe, 1995). Moreover, in the present study, children were given a cautionary instruction and told that some of the context items may have been 'mixed up' and therefore be different to those that they had originally seen, and this may have contributed to their accuracy when presented with distracter items.

At face value these findings suggest that there may be no costs associated with trying to enhance recall with context reinstatement, only potential benefits. However, there are reasons to be cautious about reaching such a conclusion. First, more than half of the children who were interviewed in the imperfect-context referred to the actual distracter items they saw, at least once. From an eyewitness memory and legal perspective, even a single error can have serious consequences especially when it occurs with context reinstatement; an error originating from the physical items present at a crime scene may take on additional importance, seem more convincing, and be difficult to discount. Second, not only did children presented with distracter items make distracter-related errors when they were presented in the interview, the errors persisted to the second 6-month interview, 24 hours later, when the items were not present at the time of the interview. Whether or not they would persist over longer time delays is not yet clear. Third, the degree to which distracter items relate to the overall 'gist' of what is being recalled may affect the likelihood of making distracter-related errors (Brainerd, Reyna, \& Forrest, 2002). In the present study, the distracter items did not have a high degree of consistency with the gist of a 'pirate event', and this may therefore account for why so few distracter-related errors were made. In the real world, it is easy to imagine that changes that occur to a crime scene over time may be consistent with the gist of the context in question, that is, physical changes that do not look out of place. Moreover, the probability of making distracterrelated errors when distracters are consistent with the gist is greater for older compared to younger children; because older children have more knowledge about gist they are more likely to incorporate gist-related information into their recall and therefore also make gistrelated errors (Brainerd et al., 2002).

Reinstating the physical context perfectly, however, increased the accuracy of new information reported in both 6-month interviews; again the effect of context reinstatement persisted at least over a 24-hour delay. Instances in the children's eyewitness-memory literature in which the accuracy of new information has been enhanced are sparse. 
Exceptions include Salmon and Pipe (1997) who found that the accuracy of new information 1 year after the initial 3-day interview was most accurate when 3- to 5-year-old children were interviewed using either verbal prompts, or real props, compared with toy prop items. Salmon and Pipe (2000) tested 5-year-old children's memory for a real-life health assessment in a 3-day delay interview and again after 1 year. At the 1-year interview, new information was the most accurate for children who experienced only the verbal interview, compared with children interviewed with medical props and those who drew a picture about the medical assessment. The accuracy of additional information provided in repeated interviews is not therefore necessarily fixed, and can be enhanced under certain conditions. This notwithstanding, the accuracy of new information was always lower than that of repeated information.

We also predicted the accuracy of new information provided in the first and second 6-month interviews would differ as a function of the delay of the prior interview ( 24 hours vs. 6 months), with new information reported in the second 6-month interview being more accurate than new information reported in the first 6-month. However, this prediction was not confirmed. We unexpectedly found effects of delay, however, on the accuracy of repeated information. Repeated details from the immediate-baseline interview that were reported in the first 6-month interview (i.e. 6 months later) were more accurate than details repeated between the first and second 6-month interviews. Previous research (Pipe et al., 1999; Salmon \& Pipe, 1997, 2000) has established that repeated details are highly accurate across interviews separated by long delays and the present study confirmed this finding. It also extends it, showing that the accuracy of repeated information may depend on the delay between the interviews; Salmon and Pipe (2000) argued that across long delays errors are less stable and are less likely to be stored permanently in the memory trace than correct information. In other words, repeated information is more likely to be accurate across long delays because errors are forgotten more quickly than correct information, and less likely to be repeated. In the current study, with a short delay between the 6-month interviews, errors made in the first 6-month interview may have been remembered, not forgotten, and subsequently repeated 24 hours later. Using a false-recognition procedure, Brainerd, Reyna, and Brandse (1995) have shown that errors in the recall of word lists can be as stable as correct information across interviews separated by a week, especially when the errors are consistent with gist. In the present study, the repetition of errors across children's reports occurred even though we made no deliberate attempt to mislead the children. Instead, the interviewers gained the information from the children through openended recall, which is considered to be largely free from errors (Ceci \& Bruck, 1998), and the errors that were repeated were ones that were generated by the children themselves and incorporated into their accounts. Clearly there is a need for future research to investigate the optimal timing for repeating interviews so that the accuracy of consistent information is not compromised.

In the present study, while context reinstatement had positive effects attenuating forgetting and enhancing accuracy it did not facilitate reminiscence or reduce interview-tointerview omissions of details to the extent necessary for hypermnesia (increased recall) across repeated interviews after a 6-month delay. It therefore remains to be determined how this might be achieved in 5- and 6- year-old children's eyewitness recall after very long delays over which considerable forgetting has occurred. A limitation of this study is, of course, that only a single age group received the repeated interviews and that the repeated interviews all occurred after a 6-month delay. It is unclear whether context reinstatement would have not been more effective in facilitating reminiscence and hypermnesia if, for 
example, the delay between the event and repeated interviews had been shorter, or if older children had been included in the study. Nonetheless, the present results are encouraging from a practical perspective suggesting that context reinstatement can have a facilitative effect across repeated interviews, at least for the age group tested here. There may, therefore, be benefits of using context reinstatement when the integrity of the context can be determined, and when the context is sufficiently distinctive to serve as a useful memory cue; in real life, exact items in specific locations may change over time, and highly familiar environments may lose their effectiveness as a cue for specific episodes. Taken together, the results of this experiment show that whenever context reinstatement is considered as part of an interview strategy, the integrity of the context and the timing between interviews should be considered. Future research systematically examining the timing of repeated interviews is needed to determine when repeated interviewing is likely to be optimal, increasing recall without affecting accuracy.

\section{ACKNOWLEDGEMENTS}

We are grateful for the assistance of Deirdre Brown, Karen Daniels, Sasha Farry, Keith Garraway and Rachel Sutherland with this research project. The parents, teachers, and children of the Dunedin primary schools deserve special thanks for donating their time and resources, without which, this study would not have been possible.

\section{REFERENCES}

Ammons, H., \& Irion, A. L. (1954). A note on the Ballard reminiscence phenomenon. Journal of Experimental Psychology, 48, 184-186.

Ballard, P. B. (1913). Oblivescence and reminiscence. British Journal of Psychology, 1, 1-82.

Bluck, S., Levine, L. J., \& Laulhere, T. M. (1999). Autobiographical remembering and hypermnesia: A comparison of older and younger adults. Psychology and Aging, 14, 671-682.

Bornstien, B. H., Liebel, L. M., \& Scarberry, N. C. (1998). Repeated testing in eyewitness memory: A means to improve recall of a negative emotional event. Applied Cognitive Psychology, 12, 119131.

Brainerd, C. J., Reyna, V. F., \& Brandse, E. (1995). Are children's false memories more persistent than their true memories? Psychological Science, 6, 359-364.

Brainerd, C. J., Reyna, V. F., \& Forrest, T. J. (2002). Are young children susceptible to the falsememory illusion? Child Development, 73, 1363-1377.

Brainerd, C. J., Reyna, V. F., Howe, M. L., \& Kingma, J. (1990). The development of forgetting and reminiscence. Monographs of the Society for Research in Child Development, 55 (Serial No. 222).

Ceci, S., \& Bruck, M. (1993). Suggestibility of the child witness: A historical review and synthesis. Psychological Bulletin, 113, 403-439.

Ceci, S., \& Bruck, M. (1998). Children's testimony: Applied and basic issues. In I. E. Sigel, \& K. A. Renninger (Eds.), Handbook of child psychology: Child psychology in practice (Vol. 4, 5th ed., pp. 713-774). New York: John Wiley \& Sons Inc.

Cohen, J. (1988). Statistical power analysis for the behavioral sciences (2nd ed.). New York: Academic Press.

Dunning, D., \& Stern, L. B. (1992). Examining the generality of eyewitness hypermnesia: A close look at time delay and question type. Applied Cognitive Psychology, 6, 643-657.

Erdelyi, M. H. (1996). The recovery of unconscious memories: Hypermnesia and reminiscence. Chicago: University of Chicago Press. 
Erdelyi, M. H., \& Becker, J. (1974). Hypermnesia for pictures: Incremental memory for pictures but not words in multiple recall trials. Cognitive Psychology, 6, 159-171.

Gee, S., \& Pipe, M.-E. (1995). Helping children to remember: The influence of object cues on children's accounts of a real event. Developmental Psychology, 31, 746-758.

Godden, D., \& Baddeley, A. (1980). When does context influence recognition memory. British Journal of Psychology, 71, 99-104.

Hayne, H., \& Rovee-Collier, C. (1995). The organization of reactivated memory in infancy. Child Development, 66, 893-906.

Hershkowitz, I., Orbach, Y., Lamb, M. E., Sternberg, K. J., Horowitz, D., \& Hovav, M. (1998). Visiting the scene of the crime: Effects on children's recall of alleged abuse. Legal and Criminological Psychology, 3, 195-207.

Howe, M. L., Kelland, A., Bryant-Brown, L., \& Clark, S. L. (1992). Measuring the development of children's amnesia and hypermnesia. In M. L. Howe, C. J. Brainerd, \& V. F. Reyna (Eds.), Development of long-term retention (pp. 56-102). New York: Springer-Verlag.

Jones, C. H., \& Pipe, M.-E. (2002). How quickly do children forget events? A systematic study of children's event reports as a function of delay. Applied Cognitive Psychology, 16, 755-768.

La Rooy, D., Pipe, M.-E., \& Murray, J. E. (2005). Reminiscence and hypermnesia in children's eyewitness memory. Journal of Experimental Child Psychology, 90, 235-254.

Leichtman, M. D., \& Ceci, S. J. (1995). The effects of stereotypes and suggestions on preschoolers' reports. Developmental Psychology, 31, 568-578.

Malloy, L., Lyon, T. D., \& Quas, J. A. (2005). Recantation of substantiated child sexual abuse allegations. In preparation.

McCauley, M. R., \& Fisher, R. P. (1995). Facilitating children's eyewitness recall with a revised cognitive interview. Journal of Applied Psychology, 80, 510-516.

Memon, A., Wark, L., Bull, R., \& Koehnken, G. (1997). Isolating the effects of the cognitive interview techniques. British Journal of Psychology, 88, 179-197.

Murachver, T., Pipe, M.-E., Gordon, R., Owens, J. L., \& Fivush, R. (1996). Do, show, and tell: Children's event memories acquired through direct experience, observation, and stories. Child Development, 67, 3029-3044.

Orbach, Y., Hershkowitz, I., Lamb, M. E., Sternberg, K. J., \& Horowitz, D. (2000). Interviewing at the scene of the crime: Effects on children's recall of alleged abuse. Legal and Criminological Psychology, 5, 135-147.

Paris, S. G. (1978). Memory organization during children's repeated recall. Developmental Psychology, 14, 99-106.

Payne, D. G. (1986). Hypermnesia for pictures and words: Testing the recall level hypothesis. Journal of Experimental Psychology: Learning, Memory, and Cognition, 12, 16-29.

Payne, D. G. (1987). Hypermnesia and reminiscence in recall: A historical and empirical review. Psychological Bulletin, 101, 5-27.

Peterson, C., Moores, L., \& White, G. (2001). Recounting the same events again and again: Children's consistency across multiple interviews. Applied Cognitive Psychology, 15, 353-371.

Pipe, M.-E., Gee, S., Wilson, J. C., \& Egerton, J. M. (1999). Children's recall 1 or 2 years after an event. Developmental Psychology, 35, 781-789.

Pipe, M.-E., \& Wilson, J. C. (1994). Cues and secrets: Influences on children's event reports. Developmental Psychology, 30, 515-525.

Plotnikoff, J., \& Woolfson, R. (2001). An evaluation of child witness support. Scottish Executive Central Research Unit. Report available from: http://www.scotland.gov.uk/cru/kd01/purple/witness01.pdf

Priestley, G., Roberts, S., \& Pipe, M.-E. (1999). Returning to the scene: Reminders and context reinstatement enhance children's recall. Developmental Psychology, 35, 1006-1019.

Roediger, H. L., III, \& Payne, D. G. (1982). Hypermnesia: The role of repeated testing. Journal of Experimental Psychology: Learning, Memory and Cognition, 8, 66-72.

Rovee-Collier, C. (1995). Time windows in cognitive development. Developmental Psychology, 35, 1006-1019.

Rovee-Collier, C., Hayne, H., \& Colombo, M. (2000). The development of implicit and explicit memory. Amsterdam/Philadelphia: John Benjamins Publishing Company.

Salmon, K., Bidrose, S., \& Pipe, M.-E. (1995). Providing props to facilitate children's event reports: A comparison of toys and real items. Journal of Experimental Child Psychology, 60, 174-194. 
Salmon, K., \& Pipe, M.-E. (1997). Props and children's event reports: The impact of a 1-year delay. Journal of Experimental Child Psychology, 65, 261-292.

Salmon, K., \& Pipe, M.-E. (2000). Recalling an event one year later: The impact of props, drawing and a prior interview. Applied Cognitive Psychology, 14, 99-120.

Saywitz, K. J., Geiselman, R. E., \& Bornstein, G. K. (1992). Effects of cognitive interviewing and practice on children's recall performance. Journal of Applied Psychology, 77, 744-756.

Scrivner, E., \& Safer, M. A. (1988). Eyewitnesses show hypermnesia for details about a violent event. Journal of Applied Psychology, 73, 371-377.

Sheffield, E. G., \& Hudson, J. A. (1994). Reactivation of toddlers' event memory. Memory, 2, 447465.

Spear, N. E. (1973). Retrieval of memories in animals. Psychological Review, 80, 163-194.

Steward, M. S., Steward, D. S., Farquhar, L., Myers, J. E. B., Reinhart, M., Welker, J., Joyce, N., Driskill, J., Morgan, J. (1996). Interviewing young children about body touch and handling. Monographs of the Society for Research in Child Development, 57 (Serial No. 248).

Tinsley, H. E. A., \& Weiss, D. J. (2000). Interrater reliability and agreement. In H. E. A. Tinsley, \& S. D. Brown (Eds.), Applied multuvariate statistics and mathematical modeling (pp. 95-124). San Diego, CA: Academic Press.

Tulving, E., \& Thomson, D. M. (1973). Encoding specificity and retrieval processes in episodic memory. Psychological Review, 80, 352-373.

Wilkinson, J. (1988). Context effects in children's event memory. In M. M. Gruneberg, P. E. Morris, $\&$ R. N. Sykes (Eds.), Practical aspects of memory: Current research issues (Vol. 1, pp. 107-111). New York: Wiley.

Wilson, J. C., \& Pipe, M.-E. (1989). The effects of cues on young children's recall of real events. New Zealand Journal of Psychology, 18, 65-70.

Zar, J. H. (1996). Biostatistical analysis (3rd ed.). New Jersey: Prentice Hall. 